\title{
Teachers' professional goal orientations: Importance for further training and sick leave
}

\author{
Sebastian Nitsche ${ }^{\mathrm{a}, *}$, Oliver Dickhäuser ${ }^{\mathrm{a}}$, Michaela S. Fasching ${ }^{\mathrm{b}}$, Markus Dresel ${ }^{\mathrm{b}}$ \\ a Department of Psychology, University of Mannheim, 68131 Mannheim, Germany \\ ${ }^{\mathrm{b}}$ Department of Psychology, University of Augsburg, Universitätsstraße 10, 86135 Augsburg, Germany
}

\section{Theoretical background}

Reform efforts within the school system widely rely on teachers, but changes in the classroom and during lessons require a great deal of learning and can only be achieved if teachers have appropriate support and show the necessary will to reconstruct their practice (see Borko, 2004; Spillane, 1999). Recent approaches have even called for lifelong learning and continuous improvement of professional skills among teachers (Borko, 2004). At the same time, however, several studies on teacher burnout have shown that the daily workload of teachers is characterized by a high degree of stress, which-for many teachers-results in a depressed mood, poor performance, impaired health, and even premature retirement (see Burke, Greenglass, \& Schwarzer, 1996).

Despite these high demands within the teaching profession, there are some teachers who seem to be more successful than others at coping with daily demands while still having the capacity for further qualification and self-improvement-all of which raises the question of possible individual determinants. In the present study, we wish to determine the role of goal orientations as an element of professional motivation for teachers' attitudes and behavior toward professional development (indicated by the attitude toward further training and the number of attended trainings) and for their degree of vocational

\footnotetext{
* Corresponding author. Tel.: + 49621181 2210; fax: + 496211812206

E-mail addresses: sebastian.nitsche@uni-mannheim.de (S. Nitsche). oliver.dickhaeuser@uni-mannheim.de (0. Dickhäuser), michaela.fasching@phil.uni-augsburg.de (M.S. Fasching), markus.dresel@phil.uni-augsburg.de (M. Dresel).
}

burden (indicated by perceived occupational strain and the number of sick days).

\subsection{Teachers' goal orientations}

Goal orientations (also named achievement goals) define why and how people are trying to achieve various objectives in achievement settings and thus provide a framework for extensive research on motivational orientations that contributes to individuals' adaptive and maladaptive patterns of engagement (Kaplan \& Maehr, 2007). Only recently the concept of goal orientations was applied to the description and analysis of professional motivation among teachers (Butler, 2007) and an increasing body of work has focused on the effects of professional goal orientations on teaching and teachers' characteristics (Butler \& Shibaz, 2008; Fasching, Dresel, Dickhäuser, \& Nitsche, 2011; Nitsche, Dickhäuser, Fasching, \& Dresel, 2011; Retelsdorf, Butler, Streblow, \& Schiefele, 2010). The idea of applying goal orientation theory to the topic of teacher motivation essentially rests on the assumption that teachers differ in the extent to which they interpret their own professional activities as learning and/or achievement oriented. Based on the conceptualizations of Dweck and Leggett (1988), Elliot and Church (1997) as well as Nicholls (1989), the literature on teachers' goal orientations differentiates four distinct dimensions: learning goal orientation (the desire to increase one's own competencies), performance approach goal orientation (the desire to demonstrate higher competencies than other teachers), performance avoidance goal orientation (the desire to hide lower competencies than other teachers) and finally, work avoidance (the desire to reduce one's workload as much as possible). 
The goal orientation approach proposes that goals individuals are pursuing create the framework within which they interpret and react to events and result in different patterns of affect, cognition and behavior (e.g., Dweck \& Leggett, 1988). Following this idea, the next two sections will present theoretical considerations and empirical indications why teachers' goal orientations should be important for both professional development and vocational burden.

\subsection{Goal orientations and professional development}

Goal orientations are a key variable in several models of selfregulated learning (e.g., Boekaerts \& Niemivirta, 2000; Butler \& Winne, 1995; Pintrich, 2000). According to Pintrich (2000) all models of self-regulation assume that goals serve as a "gauge against which to assess the operation of the system and then guide regulatory processes" (page 472). The orientation toward certain goals thus should elicit distinct processes of self-regulation which are beneficial to make progress toward these goals. For example, if individuals are motivated to increase their competencies (learning goal orientation), they should orient their monitoring processes to cues that show progress in learning and approach more learning opportunities. In contrast, if individuals are motivated to demonstrate higher competencies than others (performance approach goal orientation) or hide a presumed lack of competencies (performance avoidance goal orientation), they should orient their monitoring processes to the comparison with others and use regulation strategies that maximize the probability to show superior and not inferior performance respectively. Although work avoidance is not included in Pintrich's models of self-regulated learning (Pintrich, 2000), it is reasonable to assume that individuals with a higher work avoidance invest less effort and are primarily concerned with finishing their duties quickly (Urdan, 1997).

Even though these theoretical assumptions for goal orientations are in line with empirical research on students (see Kaplan \& Maehr, 2007; Pintrich, 2000 for a review), the relevance of goal orientations for teachers' learning and professional development had not been addressed, yet. However, recent studies indicate that goal orientations may be similarly important for the initiation and regulation of competence-related activities in teachers. Learning goal orientation could be associated with higher professional reflection, greater interest in teaching, higher self-efficacy, the perception of help seeking as beneficial and a preference for autonomous help that enables teachers to solve future job-related problems on their own (Butler, 2007; Dickhäuser, Butler, \& Tönjes, 2007; Nitsche et al., 2011; Retelsdorf et al., 2010; Runhaar, Sanders, \& Yang, 2010). Performance approach goal orientation was related only to higher self-efficacy (Nitsche et al., 2011). By contrast, performance avoidance goal orientation was associated with lower self-efficacy, the perception of help seeking as threatening and less frequent utilization of collegial help (Butler, 2007; Nitsche et al., 2011) and work avoidance was associated with less interest in teaching activities, the perception of help seeking as expedient and a preference for expedient help (Butler, 2007; Nitsche et al., 2011; Retelsdorf et al., 2010).

Although these results urge the importance of goal orientations for competence-related attitudes and behavior in teachers, there are, as yet, no studies that examine the role of goal orientations for teachers' learning and professional development. In order to expand our knowledge of how individual motivational factors are related to teachers' attitudes and behavior toward professional development, the first objective of the present study is to examine whether goal orientations can predict (a) individual attitudes toward further training and (b) the number of attended training workshops.

Since learning goal orientation is concerned with improving professional skills and knowledge, we assume that individuals with a higher learning goal orientation display a more positive attitude toward further training and report a greater number of attended training workshops. In contrast, we expect that individuals with high performance avoidance goal orientation have a less positive attitude toward further training and report fewer attended training workshops, since attending such training might reveal their own deficits which, in turn, would impede their goal to hide a presumed lack of competence. Similarly, individuals displaying high work avoidance should see further training as less positive and attend such training less frequently, as further training is generally associated with additional work which, again, would be counterproductive to their own goal; namely, reducing work effort. We have no specific assumption for performance approach goal orientation, since the attendance of further training may be seen as both an opportunity to competence demonstration (which would suggest a positive association) and an indicator of competence deficits (which would suggest a negative association).

In addition, we seek to examine whether the association between goal orientations and the number of attended trainings is mediated by attitude toward further training.

\subsection{Goal orientations and vocational burden}

In line with Dweck and Leggett's (1988) assumption that goal orientations create a framework within which individuals interpret and react to events, it was argued that goal orientations may also be of particular importance for individuals' psychological and physical well-being (e.g., Dykman, 1998; Elliot \& Sheldon, 1997; Kaplan \& Maehr, 1999). Dweck and Leggett (1988) initially pointed out that, in the face of failure, individuals with a high learning goal orientation show a "mastery-oriented" response pattern (including constructive self-instructions and self-monitoring, optimism, positive affect, and effective problem-solving strategies) whereas individuals with a high performance goal orientation who perceive their abilities to be low show a "helpless" response pattern (including avoidance of challenge, negative self-cognitions, negative affect and impaired performance). Kaplan and Maehr (1999) argued that, in the long term, such differing experiences of failure would influence individuals well-being beyond situational affect. Elliot and Church (1997) refined the statement about performance goal orientation and suggested that only the pursuit of performance avoidance goals, but not performance approach goals is characterized as self-regulation according to potential negative outcomes. Following Elliot and Sheldon (1998) as well as Elliot, Thrash, and Murayama (2011), this focus on negative outcomes and this use of negative possibilities as the hub of self-regulation is likely to evoke a variety of maladaptive cognitive and affective processes (like threat appraisal, worries, distraction, anxiety, low perceived progress, rumination and sensitivity to negative information) that are detrimental to psychological well-being and physical health.

In line with these assumptions, several empirical studies indicated performance avoidance goal orientation to be a negative predictor and learning goal orientation to be a positive predictor of psychological and physical well-being (e.g., Dykman, 1998; Elliot \& McGregor, 2001; Elliot \& Sheldon, 1997, 1998; Elliot et al., 2011; Finsterwald, Ziegler, \& Dresel, 2009; Kaplan \& Maehr, 1999).

Applying this line of reasoning to the teaching profession it can be argued that teachers' goal orientations affect the handling of failure and setbacks as well as the experience of vocational burden. Accordingly, several studies found learning goal orientation to be associated with lower symptoms of burnout whereas performance avoidance goal orientation was associated with higher burnout symptoms (Retelsdorf et al., 2010; Tönjes \& Dickhäuser, 2009; Tönjes, Dickhäuser, \& Kröner, 2008). Beyond that, even work avoidance was associated with higher burnout (Retelsdorf et al., 2010). Although work avoidance was never explicitly considered in relation to students' well-being, it appears to be associated with a more negative cognition and behavior pattern, similar to a performance avoidance 
goal orientation (see Archer, 1994; Duda \& Nicholls, 1992; Nicholls, Patashnick, \& Nolen, 1985; Skaalvik, 1997).

It must be mentioned, that all studies linking teachers' goal orientations and burnout as well as most research on students exclusively assessed individuals' self perceptions without taking any behaviorbased indicators into account (see Elliot \& McGregor, 2001 for an exception). Thus, the second objective of the present study is to examine the extent to which teachers' goal orientations-in addition to predicting perceived occupational strain-predict teachers' sick leave as reflected by the number of sick days taken. Based on the aforementioned considerations and findings, we hypothesize that learning goal orientation is a negative predictor, and conversely that performance avoidance goal orientation is a positive predictor, of perceived occupational strain and the number of sick days taken. Since work avoidance has been found to be linked with a more maladaptive behavior pattern (Archer, 1994) and has been found to predict higher burnout among teachers (Retelsdorf et al., 2010), we expect that work avoidance is also a positive predictor of perceived occupational strain and the number of sick days. In addition, we wish to examine whether the relationship between goal orientations and sick days is mediated by perceived occupational strain.

\subsection{Hypotheses}

Concerning further training, we propose the following hypotheses:

The more teachers are interested in increasing their competencies (learning goal orientation), the more positive will be their attitude toward further training (Hypothesis 1a) and the more training workshops they will report having attended (Hypothesis 1b). The more teachers aim to hide a presumed lack of competence (performance avoidance goal orientation), the more negative will be their attitude toward further training (Hypothesis $2 a$ ) and the less frequently they will have participated in training workshops (Hypothesis 2b). The more teachers are interested in reducing their workload (work avoidance), the more negative will be their attitude toward further training (Hypothesis 3a) and the fewer attended training workshops they will report (Hypothesis 3b). Additionally, we aim to examine whether the proposed associations between goal orientations and the number of attended trainings is mediated by teachers' attitude toward further training.

Concerning vocational burden, we propose the following hypotheses:

The more teachers are interested in increasing their competencies (learning goal orientation), the less occupational strain they perceive (Hypothesis $4 \mathrm{a}$ ) and the fewer sick days they report (Hypothesis $4 \mathrm{~b}$ ). The more teachers wish to hide presumed incompetence from others (performance avoidance goal orientation), the more occupational strain they perceive (Hypothesis 5a) and the more sick days they report (Hypothesis $5 b$ ). The more strongly teachers aim to reduce their work load (work avoidance), the more occupational strain they perceive (Hypothesis 6a) and the more sick days they report (Hypothesis 6b). Additionally, we aim to examine whether the assumed connection between goal orientations and sick days is mediated by perceived occupational strain.

Due to inconsistent predictions and findings with regard to performance approach goal orientation, we did not propose specific assumptions for this goal orientation.

\section{Methods}

\subsection{Sample}

Our sample ${ }^{1}$ consisted of 224 teachers (67.1\% female) between the ages of 25 to 69 years $(M=41.4 ; S D=11.6)$. The average length 1 Although the current sample was also included in the validation of the applied goal
orientation measure (see Nitsche et al., 2011), the current research questions are focused for the first time. of service as a teacher was 13.7 years $(S D=11.8)$. The sample included teachers from different federal states and all tracks of the German school system; $12 \%$ elementary school, $20.4 \%$ lower track secondary schools (Hauptschule), 18.8\% intermediate track secondary schools (Realschule), and $45.5 \%$ academic track secondary schools (Gymnasium). Approximately $3.1 \%$ of participants were teaching within a different track (comprehensive school, vocational school, etc.). Teachers had been contacted via email through their school administration and were asked to take part in a 30-minute online survey on attitudes and goal orientations among teachers. Participation was strictly voluntary and anonymous.

\subsection{Instruments}

The assessment of professional goal orientations among teachers was carried out by means of the goal orientation questionnaire by Nitsche et al. (2011), which allows for the differentiation of competence-specific facets of learning goal orientation as well as addressee-specific facets of performance approach and performance avoidance goal orientation. In the present work, we focused on the main dimensions of goal orientations; learning goal orientation (Cronbach's $\alpha=.87$; item example: "In my vocation, I aspire to increasingly understand complicated class situations"), performance approach goal orientation $(\alpha=.94$; item example: "In my vocation, I aspire to demonstrate to my colleagues that I know more than other teachers"), performance avoidance goal orientation $(\alpha=.92$; item example: "In my vocation, I aspire to conceal from my colleagues when I do something less satisfying than other teachers"), and work avoidance $(\alpha=.79$; item example: "In my vocation, I aspire to get through the day with little effort"). The instrument included 36 items with a 5-point Likert-type scale ranging from 1 (strongly disagree) to 5 (strongly agree). The validity of the questionnaire could be demonstrated by confirmatory factor analyses and differential associations to self-efficacy and help-seeking (Nitsche et al., 2011).

Teachers' individual attitude toward further training was assessed using the scale Einstellung zur Fortbildung (attitude toward further training) by Abs, Döbrich, Gerlach-Jahn, and Klieme (2009). Based on seven items, this one-dimensional scale assesses how positively or negatively teachers generally feel toward further training ( $\alpha=$ .78) using a 4-point Likert-type scale ranging from 1 (strongly disagree) to 4 (strongly agree). Higher values indicated a more positive attitude toward further training. One item, for example, assessed attitude with the phrase "I believe that further training is important for professional well-being and success even after completion of teacher training". An exploratory factor analysis with parallel analysis and Velicer's MAP test (see O'Connor, 2000) confirmed the onedimensional structure proposed by Abs et al. (2009).

The number of attended trainings was assessed by a single item, asking "How many training workshops did you attend during the previous school year?"

For the assessment of perceived occupational strain, we used the scale Berufliche Belastung (occupational strain) by Enzmann and Kleiber (1989). The scale includes 15 items assessing aspects of perceived overload, external control, and occupational dissatisfaction $(\alpha=88)$. Schmitz (2000) reported re-test-reliabilities over one year between .70 and .75 and significant correlations of the subcomponents to the dimensions of the Maslach Burnout Inventory $(.19 \leq \mathrm{r} \leq .80)$. Answers were assessed by a 5 -point Likert-type scale ranging from 1 (strongly disagree) to 5 (strongly agree). One of the items, for example, seeks teachers' response to the statement "I rarely feel that I can truly unwind". We conducted an exploratory factor analysis to identify the number of factors suggested by the data. According to parallel analysis and Velicer's MAP test (O'Connor, 2000) the scale is best represented onedimensionally. 
Table 1

Means, standard deviations and Spearman correlations of variables.

\begin{tabular}{|c|c|c|c|c|c|c|c|c|c|}
\hline & $M$ & $S D$ & $(1)$ & $(2)$ & (3) & $(4)$ & $(5)$ & (6) & $(7)$ \\
\hline (1) Learning goal orientation & 4.19 & 0.55 & - & - & - & - & - & - & - \\
\hline (2) Performance approach goal orientation & 2.34 & 0.87 & -.03 & - & - & - & - & - & - \\
\hline (3) Performance avoidance goal orientation & 2.48 & 0.81 & -.05 & $.73^{* * *}$ & - & - & - & - & - \\
\hline (4) Work avoidance & 2.39 & 0.97 & -.11 & $.13^{*}$ & $.22^{* * *}$ & - & - & - & - \\
\hline (5) Attitude toward further training & 3.15 & 0.57 & $35^{* * *}$ & -.08 & $-.19^{* *}$ & -.05 & - & - & - \\
\hline (6) Number of attended training workshops & 2.76 & 2.09 & $.24^{* * *}$ & -.03 & -.11 & $-.18^{* *}$ & $.20^{* *}$ & - & - \\
\hline (7) Perceived occupational strain & 2.13 & 0.59 & $-.17^{* *}$ & $.24^{* * *}$ & $.36^{* * *}$ & $29^{* * *}$ & $-.15^{*}$ & -.13 & - \\
\hline (8) Number of reported sick days & 4.61 & 6.37 & -.03 & -.05 & .01 & .06 & -.03 & -.03 & .10 \\
\hline
\end{tabular}

$N=224 .{ }^{*} p<.05,{ }^{* *} p<.01,{ }^{* * *} p<.001$.

Finally, the number of sick days was assessed by the single item "Please indicate how many days you were not able to work during the previous year due to own illness."

\section{Results}

For data analysis, IBM Statistics SPSS 19 was used. Table 1 displays the means, standard deviations, and Spearman correlations ${ }^{2}$ of all variables. Compared to the possible value range, the mean score of the learning goal orientation scale was relatively high, while the standard deviation was lower than the standard deviations of the other goal orientation scales. This may indicate a ceiling effect, which compromises the possibility to find the assumed effects for learning goal orientation. Still, correlations with other goal orientations as well as the included dependent variables (except for the number of sick days) are in line with former findings (Nitsche et al., 2011; Retelsdorf et al., 2010; Tönjes et al, 2008) and our assumptions.

For the number of further trainings and the number of sick days, we found relatively high standard deviations compared with the respective mean. This is due to the fact that count variables (like the number of further trainings and the number of sick days) typically tend to be positively skewed (see Long, 1997). As these variables are not normally distributed, the application of a linear regression model would yield inconsistent and distorted estimates (Long, 1997). To avoid this problem, we used Poisson regressions to predict the number of attended trainings and the number of sick days.

To determine our mediation assumptions, we tested the following conditions in accordance with Baron and Kenny (1986): (a) the independent variable significantly predicts the mediator; (b) the independent variable significantly predicts the dependent variable; and (c) controlling for the independent variable, the dependent variable is predicted by the mediator. For the statistical confirmation of mediator effects, we applied a Monte Carlo method by Selig and Preacher (2008), which-compared with the commonly used Sobel Test-allows for more precise estimates (see MacKinnon, Lockwood, \& Williams, 2004).

\subsection{Predicting aspects of further training}

\subsubsection{Positive attitude toward further training}

The linear regression used to predict teachers' attitude toward further training was significant $\left(F(4,219)=10.0, p<.001, R^{2}=.15\right)$. As expected, learning goal orientation was confirmed as a significant positive predictor of a positive attitude toward further training $(\beta=$ $.35, p<.001)$ and performance avoidance goal orientation proved to

\footnotetext{
${ }^{2}$ Since count variables (such as the number of further training and the number of sick days) are not normally distributed, Spearman correlations are used instead of Pearson-correlations.
}

Table 2

Poisson-regressions for predicting the number of attended training workshops.

\begin{tabular}{lllllllll}
\hline & \multicolumn{3}{c}{ Model 1 } & & \multicolumn{3}{c}{ Model 2} \\
\cline { 2 - 3 } \cline { 8 - 9 } Predictors & $B$ & $S E$ & $p$ & & $B$ & $S E$ & $p$ \\
\hline Learning goal orientation & .21 & .077 & .007 & & .18 & .082 & .025 \\
Performance approach goal orientation & .10 & .069 & .148 & & .09 & .069 & .173 \\
Performance avoidance goal orientation & -.12 & .076 & .109 & -.11 & .077 & .160 \\
Work avoidance & -.10 & .044 & .024 & -.10 & .044 & .022 \\
Attitude toward further training & - & - & - & .09 & .078 & .270 \\
\hline
\end{tabular}

$N=224$.

be a negative predictor of a positive attitude toward further training $(\beta=-.22, p=.019)$. Neither performance approach goal orientation $(\beta=.10$, n.s.) nor work avoidance $(\beta=.01$, n.s.) was a significant predictor of a positive attitude toward further training.

\subsubsection{Number of attended trainings}

As the number of training workshops involves a count variable, we applied Poisson regressions to predict the number of attended trainings (see Long, 1997). Within a first model, we included all four goal orientations as predictors $\left(\chi^{2}(4)=19.11, p<.001\right)$. As expected, learning goal orientation proved to be a positive predictor of the number of trainings attended, while work avoidance was shown to be a negative predictor. Contrary to our assumptions, performance avoidance goal orientation was not a significant predictor (see Table 2, Model 1).

To test our assumption on mediation, we included teachers' attitude toward further training as an additional predictor in a second model $\left(\chi^{2}(5)=20.34, p=.001\right)$. The effects of learning goal orientation and work avoidance on the number of trainings were still significant when teachers' attitude toward further training was included. However, attitude toward further training itself did not predict the number of attended training workshops (see Table 2, Model 2). As this would have been necessary to verify a mediating effect, we concluded that the effect of goal orientations on the number of attended training workshops is not mediated by teachers' individual attitude toward further training.

Because Poisson regression analysis does not assume a linear, but a log-linear association between predictors and dependent variable, regression coefficients cannot be interpreted as in linear regressions because the regression coefficients themselves depend on the values of the predictors (see Long, 1997). According to Long (1997) as well as Atkins and Gallop (2007), however, the regression coefficients may be transformed into the percentage change in the expected counts of the dependent variable, and thus more readily interpreted. ${ }^{3}$ With regard to our data (Table 2, Model 2) where we controlled for all other predictors, each

\footnotetext{
${ }^{3}$ To convert regression coefficients into the percentage change in the expected counts of the dependent variable, we used the formula suggested by Atkins and Gallop (2007): $100\left(e^{B \times \delta}-1\right)$ with $B$ representing the regression coefficient of the Poisson regression and $\delta$ representing the units of change in the predictor. Within the present study, we calculated the percentage change in the expected counts of the dependent variable for a change of one unit $(\delta=1)$ in the predictor.
} 
Table 3

Poisson-regressions for predicting the number of reported sick days.

\begin{tabular}{|c|c|c|c|c|c|c|}
\hline \multirow[b]{2}{*}{ Predictors } & \multicolumn{3}{|c|}{ Model 1} & \multicolumn{3}{|c|}{ Model 2} \\
\hline & B & SE & $p$ & B & SE & $p$ \\
\hline Learning goal orientation & -.38 & .051 & $<.001$ & -.32 & .051 & $<.001$ \\
\hline Performance approach goal orientation & -.03 & .054 & .609 & -.02 & .054 & .714 \\
\hline $\begin{array}{l}\text { Performance avoidance goal } \\
\text { orientation }\end{array}$ & .06 & .057 & .305 & -.04 & .060 & .460 \\
\hline Work avoidance & .20 & .032 & $<.001$ & .16 & .032 & $<.001$ \\
\hline Perceived occupational strain & - & - & - & .35 & .056 & $<.001$ \\
\hline
\end{tabular}

$N=224$.

increase in learning goal orientation by one unit was associated with a $19.7 \%$ increase in the expected number of attended trainings. In contrast, with each increase in work avoidance by one unit, the expected number of attended trainings decreased by $9.5 \%$.

\subsection{Predicting aspects of vocational burden}

\subsubsection{Perceived occupational strain}

Linear regression analysis used to predict perceived occupational strain based on goal orientations was found to be significant ( $F(4$ $\left.219)=13.8, p<.001, R^{2}=.20\right)$. As expected, both performance avoidance goal orientation $(\beta=.38, p<.001)$ and work avoidance $(\beta=.18$, $p=.003$ ) were confirmed to positively predict perceived occupational strain. In addition, learning goal orientation was found to be a negative predictor of perceived occupational strain $(\beta=-.14, p=.023)$. Performance approach goal orientation had no significant predictive value for teachers' perceived occupational strain $(\beta=-.06$, n.s. $)$.

\subsubsection{Number of reported sick days}

As was the case with regard to the number of attended trainings the number of sick days involved a count variable. Accordingly, we used Poisson regressions to predict the number of reported sick days (Long, 1997). In a first model, we again included all four goal orientations as predictors $\left(\chi^{2}(4)=116.18, p<.001\right)$. In line with our assumptions, work avoidance was found to be a positive predictor of the number of sick days, while learning goal orientation proved to be a negative predictor. Contrary to our assumptions, there was no association between performance avoidance goal orientation and the number of sick days (see Table 3, Model 1).

In order to assess our assumption on mediation, a second regression model was determined by incorporating perceived occupational strain as an additional predictor $\left(\chi^{2}(5)=154.92, p<.001\right)$. Even when controlling for perceived occupational strain, the effects of learning goal orientation and work avoidance on the number of reported sick days were still significant. In addition, perceived occupational strain also proved to be a significant predictor of the number of reported sick days (see Table 3, Model 2). Because both learning goal orientation and work avoidance remained significant predictors-even when controlling for perceived occupational strain-a complete mediation of effects can be excluded. To verify partial mediation, we applied the Monte Carlo method according to Selig and Preacher (2008). This analysis provided evidence for partial mediation of the effects of both learning goal orientation $(p<.05,95 \% \mathrm{CI}[-.10,-.01])$ and work avoidance $(p<.01,95 \% \mathrm{CI}[.01, .07])$ on the number of reported sick days by perceived occupational strain.

Finally, by converting the regression coefficients of our second model (Table 3, Model 2) into the percentage change in the expected counts of the dependent variable (Atkins \& Gallop, 2007), we were able to calculate that, controlling for all other predictors, each increase in learning goal orientation by one unit was associated with a $27.4 \%$ decrease in the number of expected sick days. Each increase in work avoidance by one unit was associated with a $17.4 \%$ rise in the expected number of sick days, and each increase in perceived occupational strain was associated with a $41.9 \%$ rise in the expected number of sick days.

\section{Discussion and conclusions}

The present study, for the first time, examined the extent to which individual goal orientations may be associated with teachers' attitudes and behavior toward professional development and with different aspects of vocational burden (i.e., perceived occupational strain and number of sick days). In contrast to previous studies, we did not rely solely on measures of teachers' perceptions, but also applied more objective, behavior-based measures by including the number of attended trainings and the number of reported sick days. In agreement with our hypotheses, we found that teachers who strove to increase their competencies (learning goal orientation) demonstrated a more positive attitude toward further training and attended more trainings, but also perceived less occupational strain and reported fewer sick days. Thus our findings fully confirmed our hypotheses concerning learning goal orientation (Hypothesis 1a, 1b, 4a and 4b). In line with Hypotheses $2 \mathrm{a}$ and $5 \mathrm{a}$, individuals mainly concerned with concealing presumed incompetence (performance avoidance goal orientation) showed a more negative attitude toward further training and higher perceived occupational strain. Contrary to Hypotheses $2 \mathrm{~b}$ and $5 \mathrm{~b}$, however, we did not find direct associations between performance avoidance goal orientation and behavior-based measures (i.e., number of attended trainings and number of reported sick days). One possible explanation for this missing link could be that the effects of performance avoidance goal orientation don't occur immediately, but are mediated by cognitive and affective processes that only gradually manifest in actual health problems and consequently sick days. Longitudinal studies and studies that focus on teachers with already more permanent stress symptoms may be helpful to clarify this issue. Another possible explanation for the missing links between performance avoidance goal orientation and behaviorbased measures involves the response behavior of the participants. As the items assessing performance avoidance goal orientation are inherently related to self-esteem and thus susceptible to distortion tendencies, it could be possible that the hypothesized effects may, at least in part, be hidden by systematic response bias. Such systematic bias might also be expected for the dimension of work avoidance. Indeed, we were only able to partially confirm our hypotheses concerning work avoidance since there was no association between this dimension and attitude toward further training. Although the predictive power of both scales might be limited, and the detected effects may thus only represent a lower bound, the results pattern was in line with our assumptions.

Overall, the results of the present study were in line with our assumptions that goal orientations are important motivational concepts that may be relevant for teachers' professional development as well as vocational burden and confirm findings from previous studies on burnout (Retelsdorf et al., 2010; Tönjes et al., 2008). Extending these findings, our study indicates that goal orientations offer an explanatory value for the attendance of further training and the reported number of sick days beyond teachers' attitude toward further training and perception of occupational strain. Concerning the attendance of further training, it should be mentioned that the present study may possibly underestimate the found associations because it did not differentiate between voluntarily attended and obligatory training workshops. One might expect that individual goal orientations should primarily have an effect on the attendance of training workshops if attendance is on a voluntary basis. For the attendance of obligatory trainings, however, individual motivational differences may be less important due to the contextual restrictions. 


\subsection{Limitations}

As the present study was conducted cross-sectionally, it does not permit us to draw causal conclusions from our data. Although our idea that goal orientations predict attendance of further training and sick leave is in line with goal theory, the number of trainings and sick days could only be assessed retrospectively and thus, the causal direction may just as well be inverted. Especially in cases of work avoidance, one might also assume that teachers who feel overburdened by the demands of their profession and who are already experiencing health problems could, in a next step, aim to compensate for these difficulties by reducing their workload. In support of the causal direction assumed in the present paper, Tönjes and Dickhäuser (2009) could verify a longitudinal impact of teachers' goal orientations on various aspects of burnout over a period of three months. Nonetheless, the analysis of causal direction calls for additional longitudinal and experimental studies to validate our findings.

While perceived occupational strain significantly predicted the number of sick days, the number of attended training workshops had not been significantly predicted by attitude toward further training. At first sight, this finding is unexpected because one might assume that training workshops would mainly be attended by those individuals who perceive these workshops as positive and beneficial for their professional development. While in the current study, attitude toward further training was assessed one-dimensionally, several authors argue that goal orientations are associated with qualitatively different patterns concerning the perception and interpretation of learning and performance situations (e.g., Butler \& Shibaz, 2008; Elliott \& Dweck, 1988). For example, Butler (2007) showed teachers' goal orientations to be associated with different perceptions of help seeking as beneficial, expedient, or threatening. However, not all of these perceptions had been predictive for self-reported rates of help seeking. In line with this consideration, one may similarly assume that goal orientations are associated with qualitatively different attitudes toward further training, which, in turn, may be differentially predictive for teachers' actual use of different kinds of further training and job-related learning activities. This potentially confounded assessment of qualitatively different attitudes within one dimension may also explain why, contrary to our hypothesis, we could not find a clear association between work avoidance and attitude toward further training. Further studies are needed to address this issue.

Despite the aforementioned limitations, the present study is the first to show that goal orientations are not only important with regard to teachers' perceptions and experiences, but that they are also associated with behavior-based measures of further training and sick leave among teachers.

\section{Funding acknowledgement}

This study was supported by a grant of the German Federal Ministry for Education and Research to the second author (grant number $01 \mathrm{HJ}$ 0901) and fourth author (grant number $01 \mathrm{HJ}$ 0902). The funding source was not involved in the planning, realization, analysis and data interpretation of the study.

\section{References}

Abs, H. J., Döbrich, P., Gerlach-Jahn, A., \& Klieme, E. (2009). Pädagogische Entwicklungsbilanzen an Studienseminaren (PEB-Sem). Auswahl und statistische Analyse der Erhebungsinstrumente [Pedagogical developments at training schools (PEBSem). Selection and statistical analysis of the instruments]. Materialien zur Bildungsforschung, Band 22. Frankfurt a.M: DIPF Retrieved from http:// www.pedocs.de/volltexte/2012/3126/

Archer, J. (1994). Achievement goals as a measure of motivation in university students. Contemporary Educational Psychology, 19, 430-446.

Atkins, D. C., \& Gallop, R. J. (2007). Rethinking how family researchers model infrequent outcomes: A tutorial on count regression and zero-inflated models. Journal of Family Psychology, 21, 726-735.

Baron, R. M., \& Kenny, D. A. (1986). The moderator-mediator variable distinction in social psychological research: Conceptual, strategic and statistical considerations. Journal of Personality and Social Psychology, 51, 1173-1182.
Boekaerts, M., \& Niemivirta, M. (2000). Self-regulated learning: Finding a balance between learning goals and ego-protective goals. In M. Boekaerts, P. R. Pintrich, \& M. Zeidner (Eds.), Handbook of self-regulation (pp. 417-450). San Diego: Academic Press. Borko, H. (2004). Professional development and teacher learning: Mapping the terrain. Educational Researcher, 33, 3-15.

Burke, R. J., Greenglass, E. R., \& Schwarzer, R. (1996). Predicting teacher burnout over time: Effects of work stress, social support, and self-doubts on burnout and its consequences. Anxiety, Stress, and Coping: An International Journal, 9, 1-15.

Butler, R. (2007). Teachers' achievement goal orientations and associations with teachers' help-seeking: examination of a novel approach to teacher motivation. Journal of Educational Psychology, 99, 241-252.

Butler, R., \& Shibaz, L. (2008). Achievement goals for teaching as predictors of students' perceptions of instructional practices and students' help-seeking and cheating. Learning and Instruction, 18, 453-467.

Butler, D. L., \& Winne, P. H. (1995). Feedback and self-regulated learning: A theoretical synthesis. Review of Educational Research, 65, 245-281.

Dickhäuser, O., Butler, R., \& Tönjes, B. (2007). Das zeigt doch nur, dass ich's nicht kann: Zielorientierung und Einstellung gegenüber Hilfe bei Lehramtsanwärtern [That just shows I can't do it: Goal orientation and attitudes concerning help amongst pre service teachers]. Zeitschrift für Entwicklungspsychologie und Pädagogische Psychologie, 39, 120-126

Duda, J. L., \& Nicholls, J. G. (1992). Dimensions of achievement motivation in schoolwork and sport. Journal of Educational Psychology, 84, 290-299.

Dweck, C. S., \& Leggett, E. L. (1988). A social-cognitive approach to motivation and personality. Psychological Review, 95, 256-273.

Dykman, B. M. (1998). Integrating cognitive and motivational factors in depression: Initia tests of a goal-orientation approach. Journal of Personality and Social Psychology, 74, 139-158.

Elliot, A. J., \& Church, M. A. (1997). A hierarchical model of approach and avoidance achievement motivation. Journal of Personality and Social Psychology, 72, 218-232.

Elliott, E. S., \& Dweck, C. S. (1988). Goals: An approach to motivation and achievement. Journal of Personality and Social Psychology, 54, 5-12.

Elliot, A. J., \& McGregor, H. A. (2001). A $2 \times 2$ achievement goal framework. Journal of Personality and Social Psychology, 80, 501-519.

Elliot, A. J., \& Sheldon, K. M. (1997). Avoidance achievement motivation: A personal goals analysis. Journal of Personality and Social Psychology, 73, 171-185.

Elliot, A. J., \& Sheldon, K. M. (1998). Avoidance personal goals and the personality-illness relationship. Journal of Personality and Social Psychology, 75, 1282-1299.

Elliot, A. J., Thrash, T. M., \& Murayama, K. (2011). A longitudinal analysis of selfregulation and well-being: Avoidance personal goals, avoidance coping, stress generation, and subjective well-being. Journal of Personality, 79, 643-674.

Enzmann, D., \& Kleiber, D. (1989). Helfer-Leiden: Streß und Burnout in psychosozialen Berufen [Helper-distress: Stress and burnout in psychosocial occupations]. Heidelberg. Asanger.

Fasching, M. S., Dresel, M., Dickhäuser, O., \& Nitsche, S. (2011). Goal orientations of teacher trainees: Longitudinal analysis of magnitude, change and relevance. Journal of Educational Research Online, 2, 9-33.

Finsterwald, M., Ziegler, A., \& Dresel, M. (2009). Individuelle Zielorientierung und wahrgenommene Klassenzielstruktur im Grundschulalter [Individual goal orientation and perceived classroom goal structure in primary education]. Zeitschrift für Entwicklungspsychologie und Pädagogische Psychologie, 41, 143-152.

Kaplan, A., \& Maehr, M. L. (1999). Achievement goals and student well-being. Contemporary Educational Psychology, 24, 330-358

Kaplan, A., \& Maehr, M. L. (2007). The contributions and prospects of goal orientation theory. Educational Psychology Review, 19, 141-184.

Long, J. S. (1997). Regression models for categorical and limited dependent variables. Thousand Oaks, CA: Sage Publications.

MacKinnon, D. P., Lockwood, C. M., \& Williams, J. (2004). Confidence limits for the indirect effect: Distribution of the product and resampling methods. Multivariate Behavioral Research, 39, 99-128.

Nicholls, J. G. (1989). The competitive ethos and democratic education. Cambridge, MA Harvard University Press.

Nicholls, J. G., Patashnick, M., \& Nolen, S. B. (1985). Adolescents' theories of education. Journal of Educational Psychology, 77, 683-692.

Nitsche, S., Dickhäuser, O., Fasching, M. S., \& Dresel, M. (2011). Rethinking teachers' goal orientations: Conceptual and methodological enhancements. Learning and Instruction, 21, 574-586

O'Connor, B. P. (2000). SPSS and SAS programs for determining the number of components using parallel analysis and Velicer's MAP test. Behavior Research Methods, Instrumentation, and Computers, 32, 396-402.

Pintrich, P. R. (2000). The role of goal orientation in self-regulated learning. In M. Boekaerts, P. R. Pintrich, \& M. Zeidner (Eds.), Handbook of self-regulation (pp. 451-502). San Diego: Academic Press.

Retelsdorf, J., Butler, R., Streblow, L., \& Schiefele, U. (2010). Teachers' goal orientations for teaching: Associations with instructional practices, interest in teaching, and burnout. Learning and Instruction, 20, 34-43.

Runhaar, P., Sanders, K., \& Yang, H. (2010). Stimulating teachers' reflection and feedback asking: An interplay of self-efficacy, learning goal orientation, and tranformational leadership. Teaching and Teacher Education, 26, 1154-1161.

Schmitz, G. S. (2000). Struktur und Dynamik der Selbstwirksamkeitserwartung von Lehrern. Ein protektiver Faktor gegen Belastung und Burnout? [Structure and dynamic of self efficacy in teachers. A protective factor against stress and burnout?] Berlin: Freie Universität Berlin Retrieved from http:/www.diss.fu-berlin.de/2000/29/

Selig, J. P., \& Preacher, K. J. (June). Monte Carlo method for assessing mediation: An interactive tool for creating confidence intervals for indirect effects. Available from http://www quantpsy.org 
sion]. Zeitschrift für Entwicklungspsychologie und Pädagogische Psychologie, 41 79-86.

Skaalvik, E. M. (1997). Self-enhancing and self-defeating ego orientation: Relation with task and avoidance orientation, achievement, self-perceptions, and anxiety. Journal of Educational Psychology, 89, 71-81.

Spillane, J. P. (1999). External reform initiatives and teachers' efforts to reconstruct practice: The mediating role of teachers' zones of enactment. Journal of Curriculum Studies, 31, 143-175.

Tönjes, B., \& Dickhäuser, O. (2009). Längsschnittliche Effekte von Zielorientierungen auf Dimensionen des beruflichen Belastungserlebens im Lehrerberuf [Longitudinal effects of goal orientation on factors of occupational burden in the teacher profes-
Tönjes, B., Dickhäuser, O., \& Kröner, S. (2008). Berufliche Zielorientierungen und wahrgenommener Leistungsmangel bei Lehrkräften [Goal orientation and lack of achievement in teachers]. Zeitschrift für Pädagogische Psychologie, 22, 151-160.

Urdan, T. C. (1997). Examining the relations among early adolescent students goals and friends orientation toward effort and achievement in school. Contemporary Educational Psychology, 22, 165-191. 